\title{
Power of metaphor: cultural narratives in political persuasion
}

\author{
I. V.Skrynnikova \\ Volgograd State University \\ VolSU \\ Volgograd, Russia \\ i.skrynnikova@volsu.ru
}

\author{
T. N.Astafurova \\ Volgograd State University \\ VolSU \\ Volgograd, Russia \\ t.astafurova@volsu.ru
}

\author{
N. A.Sytina \\ Volgograd State University \\ VolSU \\ Volgograd, Russia \\ n.sityna@volsu.ru
}

\begin{abstract}
The current paper deals with the influence of metaphorical framing of events on public opinion from various scholarly perspectives. Treating cultural narratives employed in public discourse as an extended metaphorical frame, the paper argues that narratives make use of archetypical plots and the shared cognitive structures of human beliefs, motivations, goals, actions, events. Being systematically exposed to certain metaphorically framed narratives, people tend to change their views of events, situations and decisions affecting their lives. The authors claim that narratives serve as a powerful tool of political persuasion and present the generic model of a narrative structure.
\end{abstract}

Keywords-metaphorical framing, narrative, event structure, image schema, plot, narrative dimensions and structure, political persuasion, public opinion.

\section{INTRODUCTION}

Recent decades have seen different research perspectives on analyzing the effects of metaphorical framing on persuasion in political and economic discourse [1-3]. Politicians and public figures systematically make use of metaphors to frame controversial political issues affecting the public. Regardless of the methodological approach taken, most scholars seem to agree that metaphorical frames affect how people view and reason about the issues. A good example is the flood metaphor, used to refer to immigration crisis in Europe, where image schemas of source domain "disaster" are mapped on the elements of the target domain "immigration" providing the negative perspective of the immigration.

Scholars from various disciplines and backgrounds who dwell on the study of metaphorical framing effects made on political persuasion adhere to different research perspectives. One of them is the response-elicitation approach (REA) [4], [5] focusing on how metaphors are processed and the ways they affect the recipients, simultaneously controlling for other factors [6]. Proponents of the critical-discourse approach argue that scholars should first look at the relation between a natural discourse and occurrences in real life to see life changes as a result of a particular metaphorical framing and systematic use of figurative language patterns [1, 2]. According to the cognitive-computational view, metaphorical frames should be looked at as a projecting narrative structure where conceptual stories are mapped by the conceptual metaphors onto everyday situations in politics and other fields. "Complex reasoning about event interactions requires not only an event description, but also a dynamic model that can simulate the execution of the event unfolding over time" [7]. Such variety of approaches sometimes yields both converging and diverging effects of metaphorical framing on power of persuasion in politics and related areas.

The purpose of the current paper is not to favour or criticize any of the approaches mentioned above, but rather to emphasize the crucial role of inherent narratives employed in public discourse. It is therefore worthwhile pointing out that a reader or listener interpreting a presented event or situation performs a mental simulation of the entailed event in a particular context. And it is a type of metaphor in a narrative he/she is exposed to that affects their understanding of events and taking a stance on an important public issue. In this paper, the authors claim that clusters of metaphors employed by the politicians form a specific type of a cultural narrative referred to as an extended metaphorical frame.

\section{DEFINING A NARRATIVE}

In communication studies, scholars have studied narrative's role in politics and their use in news media. For example, Bennett \& Edelman [8] present a pessimistic view of political narrative, arguing that narratives transmitted through mass media act as barriers to solving social problems by casting policy issues in simplistic, ideological terms (p.158). In their view, the power of narratives to label political participants as "heroes" or "villains" or "deserving" or 
"undeserving" creates "public policies that are rationalized by the construction of social problems for which they become solutions" (p. 159).

In psychological and social scientific communication research, narratives have been considered for their persuasive effects. Several theories have been presented for how narrative messages are processed by recipients. For example, Green \& Brock [9] proposed the transportation mechanism for narrative processing. The researchers hypothesized that readers may become transported into a fictional world when they become immersed in a narrative, and test the extent to which narrative transportation can influence beliefs.

In the field of cognitive linguistics, G. Lakoff and M. Johnson [10] have convincingly argued for the role of images, narrative structures and metaphors in the human language and communication in general. In their revolutionary book Metaphors We Live By (1980), they refute understanding thoughts and concepts as abstract entities and provide evidence for an embodied view of human cognition. According to their view, to understand the way people think and reason, one also has to understand one's body and emotions. In his subsequent study [11], Lakoff focuses on the fundamental dimensions of political rhetoric and points to the often overlooked importance of narratives, metaphors and emotions.

\section{A. NARRATIVE ANALYSIS}

The current paper relies on the assumption that people structure their lives by particular narratives that they are constantly exposed to, and make sense of the events in terms of narratives. Some of them are conscious while others are mostly unconscious. Let us consider the following simple narrative cited from a recent article (May 2016) in an online version of the Kommersant about corruption in Russia:

Not a single political tiger, but just a few flies were officially accused of corruption. A recent survey has shown that most Russians consider national bureaucracy incurably corrupt. Why isn't the Kremlin willing to do some cleansing, especially now when reducing losses from corruption could compensate for the fall in oil prices? The nation could have been better off.

The passage mentioned above is easy to understand, to reason about, make decisions and act correspondingly (i.e. combat corruption). First, let us note that corrupt officials are conceptualized as beasts of different types depending on an extent they are involved in corruption schemes to, and abstract actions (improving the state of the Russian national economy) as physical motions (cleansing), which prompts that the nation is an infected body. "Incurably", however, suggests that citizens have already put up with the disease, since they know it is chronic. These mappings are a part of a composite metaphorical mapping, Event Structure Metaphor, found in all languages, but the projected inferences may vary from culture to culture, being affected by underlying folk theories.

Secondly, let us mind that the complex, ongoing scenario, created by the context, encodes a negative economic situation in the country inviting a reader to consider possible aftermaths of this immoral behaviour of those in power. Thirdly, the language used in the passage involves imagining (building) alternative scenarios including goals, intentions, actions and outcomes. The use of the subjunctive "could have been" implies both disappointment by the current state of affairs and simulation of "variations on a theme", what G. Lakoff defines as 'counterfactual reasoning'. The latter is of crucial importance for other cognitive processes such as conceptual learning, decision making, social cognition, mood adjustment, and performance improvement [12].

\section{B. ASPECTS OF NARRATIVE STRUCTURE}

The comprehensive study of narrative involves analyzing several aspects of its structure:

- structural parameters in elementary narratives;

- peculiarities of composition enabling elementary narratives to combine and form more complex narratives;

- conceptual metaphors mapping elementary narrative structures onto many subject matters - from fables and fairy tales to politics and stories of scientific discovery;

- underlying pragmatic principles affecting the ways complex narratives are presented in the context.

Structural parameters of narratives are based on presenting certain moral systems and guidance on living with dignity and virtue. Old fables, fairy-tales and stories "teach" readers basic morals. One can easily find them in Aesop and Krylov's fables exposing people to the clearly-defined ways of understanding the world and guiding their moral principles. Let us consider one of I. Krylov's most famous fables "Quartet". It describes how a monkey, a donkey, a goat and a bear got their paws on some sheet music and musical instruments trying to make music together. Although they changed places several times, for some reason the result in each case was nothing but a dreadful cacophony, since none of them was a professional musician. In Russian political discussions, the plot of this fable is often resorted to describe a critical situation in the country's politics and economy which cannot be effectively resolved due to incompetence of political leaders or officials. Therefore, to any Russian, the word "quartet" immediately brings to mind Krylov's fable and is associated with ineptitude, discord and failure.

Fables are metaphorical in nature, telling overtly about animals, but covertly about people. The underlying metaphoric model found in fables is Human Character Traits Are Animal Instincts. The implication, however, is that people's actions and behaviour are similar to animals', but they can be changed since, people, unlike animals, are able to give up their bad habits and alter circumstances. To intensify the desired effect on readers' minds,politicians tend to employ the whole range of interrelated metaphoric models.

\section{NARRATIVE MESSAGE}

Each cultural narrative has its own message within a particular moral system (e.g. moral accounting principles) which structures the systems of narratives enabling them to guide human lives. A prototypical narrative includes a villain, 
a victim and a hero acting in an unfolding scenario. In the end, villains must be punished, heroes must succeed and be rewarded, and victims rescued. This leads us to recognizing the crucial role of conceptual metaphor in constituting moral systems and values, resulting in projection of narratives onto everyday situations. Interestingly enough, in some narratives, the roles of heroes and villains can overlap creating a special type of a narrative. A good example of such narrative is stories and debates on corruption in Russia in mass media, in which government agencies, involved in combating (or pretending to combat) this type of immoral behavior and being presented as heroes, are deeply involved in intricate corruption schemes themselves.

Being regularly repeated and serving as a tool of political persuasion, some narrative plots can 'wander' or 'flow' between related political areas ultimately turning into a folk belief and activating relevant frames in people's minds. This phenomenon is referred to as 'archetypical plot' [13], 'wandering plot' [14], 'nomadic plot' [15], 'floating plot' [16]. Recruiting such plots in political communication, appealing to well-established folk narratives as a pool of common feelings, ideas and images result in recognizability of a politician by his/her electorate at the unconscious level. Being resistant to "trite" political slogans and impersonal political programmes, people still listen to stories unconsciously "recognizing" perennial motifs of wars, a fighting hero attacked by numerous enemies (villains), just retribution. Thus, listeners of political stories project emotions of acceptance and admiration as well as resentment and rejection on certain politicians and public figures or current situations. In this sense, due to their universality, "floating plots" can provide possible answers to basic existential questions and prompt models of treating events from a particular angle.

From the purely cognitive perspective, folk theories are "automatic cognitive structures characterizing how things work or what properties things and people have" [7]. People act, make decisions and choices, relying on them on the regular basis. Within each culture one can find folk ideas about the human nature, causal relations, intentions, (im)moral actions, natural forces, physical laws, value of lifelong learning and work, politics, power and governance. Hence, each culture or subculture is represented by its collection of folk theories as a set of morals and underlying logics, they contribute to cultural narratives. They serve as the basis for a narrative structure and enable people to make certain inferences and draw morals. For example, let us consider Orthodox folk theory of acting morally. The common beliefs here are:

(a) some people act morally, others can commit misdeeds or crimes;

(b) the former will be rewarded while the latter inevitably punished;

(c) if an evil-doer confesses to people, he/she should be forgiven;

(d) immoral people can choose to act morally if given a chance and led by a good example; (e) people's humility and repentance will result in God's mercy.

All of these beliefs find their reflection in one type of narrative or another, permeating various areas of public governance, affecting actions and decisions of both the governing and the governed.

Following Lakoffian understanding of overall plot structure in a narrative, let us identify the following narrative dimensions: generic plot roles (e.g., Protagonist, Antagonist, Helpers), a background, a complication (a crisis), a main event (e.g., a struggle, test, trial, decision, or other crucial event), a resolution, the consequence, the moral, and alternative crisis resolution (if any). All the mentioned dimensions form a conceptually linear order in the logic of the plot.

However, in an actual story told in the language by mass media, they may follow each other in a different order depending on a type of news communicated.

Specific types of plots may fill in the overall plot structure of a narrative but with more specific content.

- These may be a hero story, a tragedy, a comedy, a love story, a detective story, a rise and a fall, a success story, a development narrative, an origin myth and so on.

- A specific plot includes specific events that fill in the parts of the overall plot structure (Background: once upon a time, in the California primary, in the Crimea referendum, etc.), a complication (The country has not calculated any risks it may take as a result of such a step), a main Event (The primary election, Brexit procedure, etc.), etc.

- Plot roles can be found within each plot type, e.g., Hero, Villain, Victim; Hero fighting many enemies at a time, his or her characteristics, obstacles on the way; beating the enemy, punishing a villain and rescuing a victim, etc.

- $\quad$ Resulting public emotional feedback to a specific plot event; e.g., anger at and disgust for a villainous action, anxiety and fear when a hero encounters a villain; relief and joy at hero's victory; pride with the victory or satisfaction with the consequence.

The basic dimensions of narrative structure are presented in Figure 1.

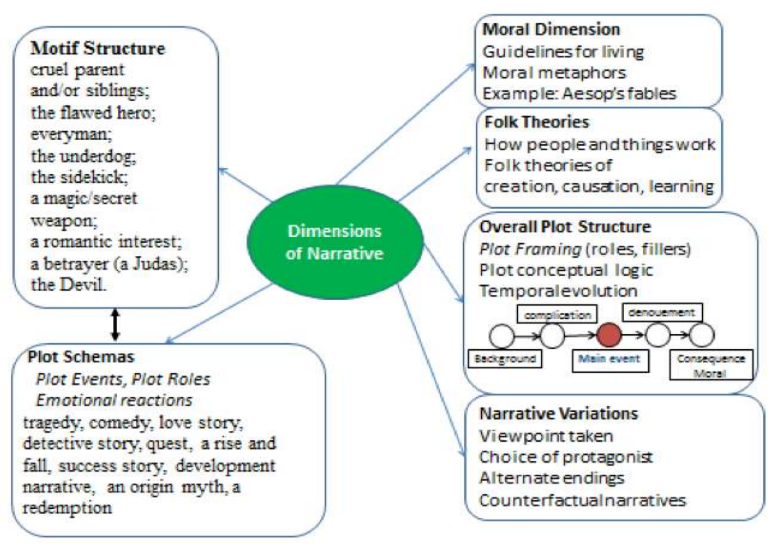

Fig.1. Dimensions of narrative structure. (adopted from G. Lakoff) [7] 
As for the motif structure, narratives can serve as a clue to understanding and describing one's life. This idea has been extensively used in psychotherapy known as metaphor therapy. A vivid example is a narrative presented in A. Grin's book, Scarlet Sails giving rise to a girls' naïve understanding of ideal love (Scarlet Sails Syndrome), where he metaphorically describes a girl whose name was Assol'. She was waiting for her handsome prince to come ashore under the scarlet sails. People laughed at her and thought her to be insane. But once upon a time she was seen sleeping in the woods by the only son of a noble family. He asked people about her, equipped his ship with scarlet sails and came to the village where Assol' lived to make her dream come true. This narrative is not only the one that young girls live by but can also be employed in the political discourse by making people believe that living a life of dignity and virtue and believing in one's own ideals can ultimately bring one happiness. This leads us to thinking that narratives may vary the viewpoint or perspective taken, the choice of protagonist (one supports or sympathizes with), and also choose an alternative ending to a classic narrative.

The political discourse most frequently employs three types of narratives: personal (a politician's narrative), ideological (a doctrine narrative), an event or situation narrative [17]. Personal narrative performs the presentational function and influences building a politician's public image. However, most researchers do not distinguish between a personal narrative and self-presentation of a politician. According to A. Duranti, personal narrative frames the sequence of a politician's life events in the way that enables $\mathrm{him} / \mathrm{her}$ to match ones of his voters [18]. In this connection, the authors find it necessary to extend the notion of personal narrative and not restrict it to a politician's self-presentation but also to include major political subjects. It may be explained by the fact that political leaders act on behalf of their nation building its image. A good example is Putin's address to Russian Duma which contains his personal narrative:

Russia is an independent, active participant of international life. Like other nations, it has its national interests which should be taken into consideration and respected [19].

In the press conference, that followed the address, positioning Russia on the international arena is not so obvious, however, one can single out a definite conceptual core concerning Russia's image in the light of the events in Ukraine: Russia is a strong democratic nation acting on the international arena on the basis of international law and able to legitimately assert its national interests. One can also trace V. Putin's personal narrative in answering questions about V. Yanukovich: e.g. Do you sympathize with him?), where he contrasts himself to the former Ukrainian leader as being a responsible political leader whose main responsibility is "to fulfill the will of the people who entrusted him the country".

Another narrative type is an ideological or doctrine narrative. Its basis is an idea or a complex of ideas underlying a party ideology. This type of narrative can be found in the closing part of Putin's presidential address where he claims that the modern Russian possesses sufficient maturity and national spirit as well as patriotic morale. It is claimed to be able to defend its foreign policy interests and retain the former power of the Russian state.

Finally, the most represented type of narrative in the political discourse is an event (situation) narrative. This type of narrative performs several functions simultaneously: 1) act as a foundation for a specific political course; 2) explains the current political situation in terms of more familiar concrete terms; 3) clarifies certain political actions and procedures. For instance, Putin's speeches and addresses feature the following topics reflected in the event narratives:

1) the political situation in Ukraine;

2) Russia's involvement in the Ukrainian conflict;

3) the so called gas issue and more broadly relations with new Ukrainian authorities;

4) interacting with the international community on the Ukrainian crisis;

5) the problem of isolation and sanctions imposed on Russia;

6) the Crimea.

\section{PLOT COMPOSITION}

A set of elementary narratives frequently makes up complex narratives. The latter were first described by George Lakoff [20] in his address to the Linguistic Society of America. It relied on Vladimir Propp's classic "Morphology of the Folktale" [21]. He points out to the different compositional principles affecting arrangement of an individual plot and narrative schemas. The following compositional principles are of particular relevance for this research.

- Conventionally conjoined subnarratives, where a hero walks a long way with many obstacles to his destination, losing a minor race, learning his lesson, and going on until he wins. An alternative plot is with someone on a quest to overcome a succession of obstacles before getting a chance with each subnarrative being a predecessor in a sequence of narratives.

- Modifying subplots (e.g., in Russian folklore or fairy tales, there is a subplot telling how a hero got his magic tool, in which he encounters the Baba Jaga or Koschej, answers three riddles and gets a reward). In the narrative of the Panama Papers, the publication of the Papers is a modifying subplot, where a part of the story is how the public turned against the off-shore investments of public officials. Such subplots play a role in a larger plot or exemplify the qualities of the hero, the villain, or victim affecting the outcome of the situation.

- In competing subplots, competing elementary narratives can be found, where "the hero of one is the villain of the other" [7]. Such subplot may feature one conquering hero, with the two subplots converging at the Main Event, namely the competition of the two heroes. 
- Motivating subplots are called so as they may motivate the main plot, for example, by reporting on the revenge for some villainy, or in general providing a rationale for the main plot.

- Foreshadowing subplots as a type of a preceding subplot have the same structure as the main plot, but with minor characters or exemplifying the threat to the hero in the plot.

\section{CONCLUSION AND DISCUSSION}

The current paper is an attempt to present a holistic view of narrative as a powerful tool of framing political and economic events. The striking effects of metaphorical framing in a narrative become particularly obvious when politicians and public figures deal with controversial issues and frame them in a way that might change people's perspective of the issue and make them change their views. However, scholars from different research background report on diverging effects of such framing depending on the methods they apply. The essential tenet of the present research is the fact that narrative exploits the rich structure of human event and action representation. Representing, reasoning about the form and content of narratives, assumes encoding this structure. The underlying finding here is that the type of metaphor in a narrative, which a person is exposed to, affects understanding the events and taking a stance on an important public issue. A set of metaphors, employed by the politicians, forms a specific type of a cultural narrative which the authors treat as an extended metaphorical frame [22]. The paper presents the examples of analyzing narratives in political communication, outlines the narrative structure and its dimensions, message they may contain, and types of plots they employ to produce a desired effect (modifying or completely changing people's perspectives).

Considering the critical role of archetypical cultural mythical plots, metaphors and images in political communication, the authors assume them to be essential in connecting the unconscious with practical application through projecting old and familiar concrete scenarios and phenomena onto complex and abstract ones. Moreover, through them, one can communicate moral principles which have been stable throughout the centuries.

Summarizing the effects of employing metaphorically framed narratives in politics and related fields, the authors find it possible to conclude that:

1) the narrative strategy of communication is a purposeful impact on a communication partner or public by resorting to various narrative plots or subplots; being particularly effective in asymmetric political communication;

2) the latter can be described as a latent state of competition for a dominant position in a communicative space, with ruling subjects experiencing certain inequality in qualitative characteristics (e.g. bilateral asymmetry where competing parties have non-matching superiority potential);

3 ) the most widespread types of narratives employed in political communication are: personal (a politician's narrative), ideological (doctrine narrative) and event (situation narrative);

4) modifying or transforming potential and diversity of political narratives as well as their efficiency speak in favour of applying them in domestic and foreign policy communication to contribute to symmetric communicative space aimed at successful cooperation rather than confrontation.

Further research into narrative requires not only an event description, but also a dynamic model that can simulate the execution of the event unfolding over time or an ongoing scenario. Such attempts have been continuously made by researchers at the International Computer Science Institute in Berkeley, California, who developed the KARMA pilot system for story understanding. Its authors claim that the system interprets newspaper story fragments in the field of international economics in the context using metaphorical projections of embodied simulations from the domains of spatial motion and manipulation onto the abstract domain of economic policies, goals, and outcomes. Similar systems for other related domains (international relations, combating terrorism, social security, etc.) need to be developed to be subsequently embedded into an integral system of story understanding.

\section{References}

[1] Ch.-Black, "Britain as a container: Immigration metaphors in the 2005 election campaign," Discourse \& Society, vol. 17(5), pp. 563-581, 2006.

[2] Musollf, "Metaphorical parasites and "parasitic" metaphors: semantic exchanges between political and scientific vocabularies," Journal of Language and Politics, vol.13 (2), pp. 218-233, 2014.

[3] G. Lakoff, The Neural Theory of Metaphor. Handbook of Metaphor. Cambridge Press, 2009.

[4] T.K. Hartman, "Toll booths on the information superhighway? policy metaphors in the case of net neutrality," Political Communication, vol. 29 (3), pp. 278-298, 2012.

[5] S. Robins, and R. E. Mayer, "The metaphor framing effect: Metaphorical reasoning about text-based dilemmas," Discourse Processes, vol. 30(1), pp. 57-86, 2000.

[6] A. Boyenaems, C. Burgers, E. Konjin, and G. Steen, "The effects of metaphorical framing on political persuasion: a systematic literature review," Metaphor and Symbol, vol. 32(2), pp.118-134, 2017.

[7] G. Lakoff, and S. Narayanan, "Towards a computational model of narrative," Proceedings of AAAI Fall Symposium: Computational Models of Narrative. AAAI Publications, 2010.

[8] W.L Bennett, and M. Edelman), "Toward a new political narrative," Journal of communication, No. 35 (4), Blackwell Publishing Ltd., pp. 156-171, 1985.

[9] M.C. Green, and T.C. Brock, "The role of transportation in the persuasiveness of public narratives," Journal of Personality and Social Psychology, No. 79 (5), pp. 701-721, 2000.

[10] G. Lakoff, and M. Johnson, Metaphors we live by. Chicago, IL: University of Chicago Press, 1980.

[11] G. Lakoff, The Political Mind: Why You Can't Understand 21st-Century American Politics with an 18th-Century Brain. Viking Adult, 2008, 304 p.

[12] G. Lakoff, Moral politics: How liberals and conservatives think. Chicago, IL: University of Chicago Press, 1996.

[13] E.M. Meletinsky, Analytical psychology and archetypes origin. http://www.gumer.info/bibliotek Buks/Literat/Article/melet2.php - date of access 17.03.2016. 
[14] V.M. Zhirmunsky, On the question of wandering narrative plots. France and Germany in Song Folklore, West and East Folklore. Comparativehistorical essays, Moscow: OGI, 2004.

[15] A.N. Veselovsky, Historical poetics. Moscow: Higher school, 1989. (in Russian).

[16] S.A. Shomova, From mystery to street-art: essays on cultural archetypes in political communication. Moscow: HSE, 2016, p. 262.

[17] E.I. Sheygal, "Multifaceted narrative," [Electronic resource], Political $\begin{array}{llll}\text { linguistics, } & \text { No. } & \text { (2) } 22, & \text { pp. 86-93, 2007. URL: }\end{array}$ http://www.philology.ru/linguistics1/sheygal-07.htm- date of access 15.02.2017.

[18] A. Duranti, "Narrating the Political Self in a Campaign for U.S. Congress," Language in Society, vol. 35 (4), pp. 467-497, 2006.

[19] Speech of President of the Russian Federation [Electronic resource]. URL: http://www.kremlin.ru/transcripts/20603 - date of access 20.07.2014

[20] G. Lakoff, Structural Complexity in Fairy Tales. The study of man, vol 1, Presented at the Summer Meeting of the Linguistic Society of America, 1972, pp.128-150.

[21] V. Propp, Morphology of the Folktale. The Hague: Mouton, 1958.

[22] K. Strkalj-Despot, I. Skrynnikova, J. Ostanina-Olszewska, The metaphorical conception of "soul" in Slavic languages. Language Contact. Proceedings of 38th Annual Meeting of Berkeley Linguistic Society. Berkeley, USA, February 12-14, 2012. 